\title{
Single layer mortars with microencapsulated PCM: Study of physical and thermal properties, and fire behaviour
}

\author{
Laia Haurie $^{1}$, Susana Serrano ${ }^{2}$, Montserrat Bosch ${ }^{1}$, Ana I. Fernandez ${ }^{3}$, Luisa F. Cabeza ${ }^{2}$ \\ ${ }^{1}$ Dept. Construccions arquitectòniques II, Universitat Politècnica de Catalunya, Barcelona, Spain, \\ Phone: 34-934016296, e-mail: laia.haurie@upc.edu \\ ${ }^{2}$ GREA Innovació Concurrent, Edifici CREA, University of Lleida, Lleida, Spain, \\ Phone: 34-973003576, Fax: 34-973003575, e-mail: lcabeza@diei.udl.cat \\ ${ }^{3}$ Department of Materials Science \& Metallurgical Engineering, University of Barcelona, Barcelona, \\ Spain, Phone: 34-934021298, e-mail: ana_inesfernandez@ub.edu
}

Corresponding author: lcabeza@diei.udl.cat

\begin{abstract}
Phase change materials are a promising strategy to reduce energy consumption in a wide range of applications including the building sector. Many studies have been done to evaluate the impact of PCM on thermal properties of building materials, however there exists little information on the influence of PCM on other properties of the support materials. This knowledge is necessary to determine the feasibility to apply and use building materials containing PCM. In this paper, the effect of the addition of different percentages of microencapsulated phase change material on the properties of two commercial single layer mortars has been studied. Physical and thermal properties as well as fire reaction have been evaluated.
\end{abstract}

Keywords: single layer mortar, coating, building, thermal properties, fire resistance, thermal energy storage

\section{Introduction}

The building sector accounted for 34\% of total global final energy use in 2010 according to the Energy Technology Perspectives (ETP) 2012 [1]. Taking into account ETP 2012 data, residential buildings used $25 \%$ of the total global final energy consumption (32\% for space heating and $2 \%$ for cooling) and commercial buildings used $9 \%$ (33\% for space heating and $7 \%$ for cooling). The building sector is therefore one of the largest end-use sectors worldwide. For this reason, the EU Member States faced new challenges with the approval of the Energy Performance of Buildings Directive (EPBD) in 2010 (Directive 2010/31/EU) [2]. The achievement of nearly-zero energy buildings in 2020 (2018 in the case of Commercial buildings) will be one of the key points by the implementation of EPBD.

In recent years, several studies have been done in order to improve the thermal response of the building envelope to achieve a reduction of the energy demand. Temperature fluctuations can be minimized providing high thermal mass into materials that compose the building envelope $[3,4$, 5]. Aste et al. 2009 [6] states that the implementation of walls with high thermal inertia reduces the energy requirements of heating and cooling systems, achieving a reduction of $10 \%$ in 
heating demand and 20\% in cooling demand. This increase of the thermal mass can be acquired by the addition of phase change materials (PCM). Izquierdo-Barrientos et al. 2013 [7] studies the optimal parameters to minimize the energy demand of a building due to heat transfer through the walls by presenting a numerical simulation (6 days winter and 6 days summer) of a typical Spanish outer wall with a PCM layer where the orientation of the wall, the position of the PCM and the temperature of the phase change are varied. The author concludes that the optimum temperature to minimize the thermal loads is not clear given a wide range of optimal temperature between $5^{\circ} \mathrm{C}$ and $35^{\circ} \mathrm{C}$. Another study of building bricks containing PCM inside its cylindrical holes has been done by Alawadhi et al. 2008 [8]. The results indicate a reduction of $17.55 \%$ of the heat flux at the indoor space when the three holes contain PCM and are placed at the centreline of the brick. Also the proper location of the PCM inside the wall composed by a $12.7 \mathrm{~mm}$ gypsum wallboard, five foam insulating layers, and a $20.5 \mathrm{~mm}$ oriented strand board (OSB), has been evaluated using a dynamic wall simulator in Jin et al. 2013 [9]. The results show an optimal location of $1 / 5 \mathrm{~L}$ from the internal surface of gypsum (being $\mathrm{L}$ the width of the wall). The peak heat flux is reduced $41 \%$ approximately in this location and the peak is shifted 2h. Furthermore, by using microencapsulated PCM the heat transfer area is increased, PCMs reactivity towards the outside is reduced and volume changes are controlled when the phase change occurs. The most common studies are done at macro-scale, by numerical simulations, or at laboratory or micro-scale in order to verify the improvement of microencapsulated PCM in the building envelope [10-15].

A proper selection of the PCM to be implemented in the constructive system is mandatory. The melting temperature of the PCM must be around the range of operation, the PCM must be chemically stable with a minimum subcooling and without increasing toxic risks. The cost is also an important parameter that must be kept low. Paraffin waxes are a good example because they have low cost, moderate thermal storage densities, a wide range of melting temperatures, negligible subcooling, are chemically inert and stable without phase segregation, but, its low thermal conductivity limits their applications [3].

Normally, PCM is placed inside the wall but there are studies that verify the improvement of thermal response of the building envelope by adding the PCM in the outer face. In [16], the author investigates the effect of the PCM placed in the outside of the building envelope by a simulation on Energy Plus program (cooling demand in Mediterranean climate). This technology offers non-invasive refurbishment in old buildings to obtain a better thermal behaviour. The higher cooling energy savings achieved are $7.2 \%$ by the installation of $3 \mathrm{~cm}$ of PCM plaster on all the exposed faces of the building vertical envelope in a semi-arid climate.

In this study, different percentages of microencapsulated PCM (0, 10 and 20\%) are added into two different types of single layer mortar (SLM) with and without colouring agent. The purpose of this material is to be implemented in the outer face of the building envelope as a finishing coating due to its water repellent properties and its aesthetic quality. SLM can be an interesting option to improve thermal behaviour of the building envelope in new buildings and refurbishments. The main difference between SLM and conventional mortar taking into account its composition is that it includes glass fibres, organic additives, mineral pigmentations and water-repellent resins, as well as cement, fine aggregates and water.

The aim of this research is to test SLM properties at micro-scale and laboratory scale in order to check the improvements of the material thermal behaviour, as well as to evaluate the 
modification of the physical and mechanical properties. Furthermore, fire reaction is also evaluated to check compliance with building codes.

\section{Materials}

Two single layer mortars (SLM), white and yellow, supplied by Weber Saint Gobain have been used in this study. The main difference between the two mortars was the presence of colouring pigments in the yellow SLM. In addition to the components of a conventional mortar, cement and fine aggregates, these SLM contain glass fibres, organic additives, mineral pigmentations, and hydrofuged resins. Micronal ${ }^{\circledR}$ DS5001 microencapsulated paraffin PCM commercialised by BASF has been added to the SLM. The melting point of Micronal ${ }^{\circledR}$ DS5001 is around $26^{\circ} \mathrm{C}$ and the heat absorption capacity is $145 \mathrm{~kJ} / \mathrm{kg}$.

Single layer mortars were prepared according to UNE-EN 1015-2 [17], using a mortar mixer with low velocity during 90s. Furthermore, water/cement was varied for each formulation to obtain a plastic consistency (UNE-EN 1015-2 [18]). The percentages of microencapsulated PCM used in this work are 0\% (M0), 10\% (M10) and 20\% (M20) in relation to the weight of the mixture of water and mortar powder. In the fresh state besides the consistency it was also determined the bulk density, which is related to the flow value [19].

\section{Mortars characterization}

In previous studies, the effect on the hydration process of conventional mortars by the addition of microencapsulated PCM has been demonstrated [19]. This change on the hydration process also affects curing process of mortar and therefore the development of physical and mechanical properties. Furthermore, the percentage variation of each material can also affect physical and mechanical properties. For this reason, SLM are evaluated at different ages in order to evaluate the effect of adding different percentages of microencapsulated PCM.

SLM are tested at early age of 7 days, 28 days, and finally at a late age of 90 days to ensure the curing process is completely finished. The testing ages were selected according to the current standards.

\subsection{Physical properties evaluation}

Bulk density is determined according to UNE-EN 1015-10 [20] applying the Eq. (1):

$$
D_{B}=M_{D} / V_{B}
$$

where

$D_{B}$ is the bulk density.

$\mathrm{M}_{\mathrm{D}}$ is the dried mass obtained after drying the sample at $35^{\circ} \mathrm{C}$ until constant mass.

$\mathrm{V}_{\mathrm{B}}$ is the bulk volume of the sample measured with a Vernier.

In order to calculate relative density and porosity, the hydrostatic weight ( $\left.\mathrm{W}_{\mathrm{HID}}\right)$ and the saturated weight ( $\mathrm{W}_{\mathrm{SAT}}$ ) must be determined. By means of a vacuum chamber, all the air is removed from the SLM sample pores and afterwards the sample is covered by $15 \mathrm{~mm}$ of water 
during 5 hours. After 5 hours, the water from the surface of the sample is removed and it is weighed on a balance to obtain the saturated weight ( $\left.\mathrm{W}_{\mathrm{SAT}}\right)$.

The relative density $\left(D_{R}\right)$ is calculated by (Eq. (2)).

$$
D_{R}=M_{D} /\left(W_{H I D}\right)-\left(W_{S A T}-M_{D}\right)
$$

The porosity of the material is the relation between the weight of the water inside the pores and the submerged weight of the sample, expressed in percentage (Eq.(3)).

$$
\text { Porosity }(\%)=\left(W_{S A T}-M_{D}\right) / W_{S A T}-\left(W_{S A T}-W_{H I D}\right) \times 100
$$

Morphology of samples and distribution of microencapsulated PCM along the mortar have been studied with a Jeol J-6510 scanning electro-microscope.

\subsection{Determination of mechanical properties}

Two tests are used during the experimentation to determine dynamic modulus of elasticity, fundamental resonance frequency and propagation of ultrasonic waves, which are classified as non-destructive tests. There have been analysed samples of the prepared SLM formulations at different ages, 7, 28 and 90 days using samples of 40x40x160mm. Values obtained are used to calculate the wave velocity and with this parameter dynamic elastic modulus can be calculated following Eq. (4):

$$
E=\rho v_{b}^{2}
$$

In the case of the fundamental resonance frequency, both longitudinal and flexural $\mathrm{MOE}_{\mathrm{D}}$ are obtained from the determination of the fundamental resonance frequency of the sample by the application of a mechanical impulse as the scheme in Figure 1 shows. This impulse, a hit with a hammer, generates sound waves through the material that are collected by a microphone. The received signal is synthetized in a software and the resonance frequency of the material (Figure $1 \mathrm{~A}$ ) is obtained. This method is based on the standard UNE- EN ISO 12680-1 [21] and it has been adapted to normalised samples RILEM of lime and cement mortars [22].

Dynamic modulus of elasticity (longitudinal) can also be calculated by the propagation of ultrasonic waves through the material. Figure $1 \mathrm{~B}$ shows the emitter and receiver of the ultrasounds that must be connected at both ends of the mortar specimen.

Compressive strength tests are carried out following the standard UNE-EN 1015-11 [23]. The equipment used is WYKEHAM FARRANCE. The load velocity used is 200N/s according to [23].

As it is specified in the standard, the samples used for compression tests result from the flexural test of three specimens of $40 \times 40 \times 160 \mathrm{~mm}$ for each formulation ( $0 \%, 10 \%$ and $20 \%$ PCM) and age (7, 28 and 90 days). The number of specimens tested under compression is, therefore, six for each formulation and age. 
The adherence test described in the standard UNE-EN 1015-12 [24], consists on the application of a perpendicular traction force on a SLM sample fixed in a holder with a 2-component resin adhesive. Samples with $40 \mathrm{~mm}$ of diameter and $18 \mathrm{~mm}$ of thickness (Figure 2A) are tested with an adhesion tester device KN-10 from NEURTEK (Figure 2B).

\subsection{Thermal analysis}

The equipment Quickline-30 manufactured by Anter Corporation is a multi-functional equipment that uses the principle of the transient heat line method to calculate thermal conductivity ( $\kappa)$ and thermal diffusivity $(\alpha)$. Measurements take only around 16-20 min. The transmitter placed on the sample surface emits heat pulses and receives the response signal of the material. It can measure thermal conductivities between $0.08-2 \mathrm{~W} / \mathrm{m} \cdot \mathrm{K}$ with a precision of $\pm 10 \%$. Measurements were performed in a conditioned room with $50 \%$ of moisture and $18-20^{\circ} \mathrm{C}$ of temperature.

A Differential Scanning Calorimeter (DSC) is used in order to analyse thermal properties of the single layer mortar. The equipment used to perform the DSC analysis was a DSC-822e commercialized by Mettler Toledo. The crucibles used were aluminium crucibles of $100 \mu \mathrm{l}$ and $3 / 4$ of volumes were filled depending on the density differences. The analyses were performed under $\mathrm{N}_{2}$ atmosphere flow of $80 \mathrm{ml} / \mathrm{min}$. A dynamic method from 20 to $50{ }^{\circ} \mathrm{C}$ and a $0.5 \mathrm{~K} / \mathrm{min}$ heating rate was used to perform the thermal characterization by DSC. Each sample was analysed 3 times in the DSC in order to calculate the enthalpy and the heat capacity.

\subsection{Fire reaction}

One of the most important concerns about the use of paraffin in buildings is its high flammability. Therefore, the study of the fire response of the SLM with microencapsulated PCM is mandatory.

A fire reaction test using an epiradiator described in the standard UNE 23721 [25] was performed on the samples to determine the time to ignition, the number of combustions and the average extent of the combustions. In this analysis, samples of 70x70x18 mm are placed on a metallic grid below a heat source of $500 \mathrm{~W}$, which is taken away and put back after each ignition and extinction during 5 minutes. The device used can be seen in Figure 3.

\section{Results and discussion}

\subsection{Physical properties}

Table 1 summarizes the values of dry weight, bulk density, relative density, and porosity of the white and yellow SLM formulations.

The results show a decrease of the bulk density by the addition of PCM. Bulk density of white SLM is reduced by $8.95 \%$ due to the addition of $10 \%$ of PCM and by $22.39 \%$ when $20 \%$ PCM is added. The decrease of the bulk density with PCM addition is slightly lower for the yellow SLM samples, $1.6 \%$ and $15.2 \%$ for $10 \%$ and $20 \%$ of PCM respectively. These variations are caused by two main reasons: the lower density of microencapsulated PCM if it is compared with 
SLM density and, the variation of porosities due to the addition of another material (microencapsulated PCM) that acts as an aggregate.

Relative density is the density of the material without taking into account the open pores. Relative density of SLM decrease with the addition of microencapsulated PCM, due to the lower density of microencapsulated PCM. Other authors have obtained similar trends for mortars and concrete containing PCM [26, 27].

Porosity values are around 50\% in all cases. Regarding the decrease in mechanical properties observed for the mortars containing PCM it was expected an increase of the porosity of the samples with PCM. Probably the reduced particle size of the microencapsulated PCM helps to keep the same values of porosity. These results differ from the ones obtained by Hunger et al. [28] in concrete - microencapsulated PCM mixtures. In their case the open porosity increases with the percentage of PCM added. A possible explanation for these differences could be related with several factors related with the formulation and mixing process. The nature of the aggregates and the intensity of the mixing process could originate breakage of the microcapsules and therefore leakage of the paraffin to the mortar, which would probably increase the porosity. Figure 4 shows the characteristics of the microencapsulated PCM used in this work, Micronal ${ }^{\circledR}$ 5001. As it can be observed Micronal ${ }^{\circledR}$ is supplied in aggregations of microcapsules forming macrocapsules for security reasons. Once the PCM is added in the final matrix the microcapsules should disperse along the material. In this case, the mixing process used to prepare the different mortars must not break the microencapsulation. Figure 5 shows SEM images of SLM M20 where microcapsules of PCM are still intact and dispersed into the cementitious matrix.

\subsection{Mechanical properties}

Results of $\mathrm{MOE}_{\mathrm{D}}$ by fundamental resonance test for compositions with 0,10 and $20 \%$ and ages of 7, 28 and 90 days are presented in Figure 6. The results show an increase of the flexural and longitudinal dynamic modulus of elasticity with the age. Nevertheless, the velocity of hardening varies depending on the amount of PCM added. In the case of the flexural $\mathrm{MOE}_{D}$ the composition without PCM achieves the $81.6 \%$ of its total flexibility during the first 7 days, and the $87.81 \%$ at 28 days of age. The composition with $10 \%$ of PCM has a slower velocity of hardening, achieving the $66.9 \%$ of its total flexibility during the first 7 days and $88.29 \%$ at 28 days. Therefore, the addition of $10 \%$ microencapsulated PCM lengthens the curing process of SLM because the hydration process is being affected. This decrease on the hydration at early stages is strongly observed in M20 samples, which achieve only $36.75 \%$ of its flexibility during the first 7 days and $39.24 \%$ at 28 days of age. These results are in good agreement with Eddhahak et al. [19] that reported a delay in the hydration process of Portland cement mortars containing microencapsulated PCM.

Moreover, final MOED is reduced by 39\% and 44\% in M10 and M20, respectively. Similar trends are observed in longitudinal modulus of elasticity.

The behaviour of the compressive strength follows the same trend tan $\mathrm{MOE}_{\mathrm{D}}$; compressive strength decreases according to the amount of microencapsulated PCM added and it increases with the age. 
The microencapsulated PCM is an organic material that do not take part in the hydration process of Portland cement, but that is avid of water. As it has been reported by Norvell et al. [29] the PCM sequesters water and hinders hydration of the mortar. For this reason the mechanical properties, especially at early stages, are lower in the mortars with PCM.

Compressive strength of M10 SLM (Figure 7) decreases 14.45\% compared to the sample without PCM at the age of 7 days, $1.90 \%$ at the age of 28 days, and $4.69 \%$ at the age of 90 days. The compressive strength of M20 SLM decreases drastically if results are compared with samples without PCM, 38.94\% at the age of 7 days, $43.81 \%$ at the age of 28 days and $59.76 \%$ at the age of 90 days. Considering the results of the M10 SLM it seems that the presence of PCM hinders the hydration of the mortar and therefore, the achievement of mechanical strengths at early stages. However, with $10 \%$ of microencapsulated PCM addition the compression strength results at 28 days are comparable with the conventional SLM. The addition of higher percentages of microencapsulated PCM penalises the compressive strength of the SLM probably due to several factors: incomplete hydration, lack of mineral aggregate, and poor compatibility between the organic PCM and the cementitious matrix.

One of the limitations in the use of PCM in cementitious-based products is the decrease of mechanical properties [5, 28, 30]. However, as single layer mortars are not designed to support high mechanical efforts they can admit a significant amount of PCM load maintaining compressive strength within an acceptable range.

The values of SLM adherence (Figure 8) are higher for the white mortar than for the yellow mortar, regardless of the amount of microencapsulated PCM added. Furthermore, the adherence is also reduced by the addition of PCM.

White SLM without PCM has an adherence of $3.37 \mathrm{~N} / \mathrm{mm}^{2}$; if a $10 \%$ of microencapsulated PCM is added into the material the adherence is reduced 0.36 times, and 0.63 times with the addition of $20 \%$ of microencapsulated PCM. Yellow SLM without PCM has lower adherence $\left(1.85 \mathrm{~N} / \mathrm{mm}^{2}\right)$ than white SLM due to the addition of the colouring agent. Adherence is reduced 0.25 times in Y/M10, and 0.43 times in Y/M20. In both SLM, results show a declining linear relationship between the addition of PCM and the adherence probably due to the low compatibility between the polymeric microcapsules and the cement.

\subsection{Thermal properties}

Figure 9 shows the results of the thermal conductivity of the different types of SLM. Microencapsulated PCM has a lower thermal conductivity $(0.18 \mathrm{~W} / \mathrm{m} \cdot \mathrm{K})$ than SLM, therefore the addition of PCM decreases the final thermal conductivity of the SLM. White SLM without PCM has a thermal conductivity of $0.51 \mathrm{~W} / \mathrm{m} \cdot \mathrm{K}$, with the addition of $10 \%$ of microencapsulated PCM the thermal conductivity decreases in $3.92 \%$, and $17.65 \%$ with $20 \%$ of microencapsulated PCM. Thermal conductivity of yellow SLM decreases slightly more with the addition of PCM obtaining $0.54 \mathrm{~W} / \mathrm{m} \cdot \mathrm{K}$ without PCM, $7.41 \%$ less with the addition of $10 \%$ of microencapsulated PCM, and $11.11 \%$ with the addition of $20 \%$ of microencapsulated PCM. In any case, white SLM has lower thermal conductivity for all the compositions.

Results in Table 2 show that yellow SLM has a thermal diffusivity slightly higher than white SLM and values decrease with the addition of PCM. 
A DSC analysis was carried out in order to calculate the enthalpy and the specific heat from DSC signal. The temperature range used in the experiments was from 10 to $50{ }^{\circ} \mathrm{C}$ and a heating rate of $0.5 \mathrm{~K} / \mathrm{min}$. The curves obtained with the DSC are presented in Figure 10. Table 3 shows the melting enthalpy obtained by the sample with $20 \%$ and $10 \%$ of microencapsulated PCM, $17.35 \mathrm{~kJ} / \mathrm{kg}$ and $8.80 \mathrm{~kJ} / \mathrm{kg}$ respectively. As expected, the amount of PCM is lower than the percentage of Micronal ${ }^{\circledR}$ added because this PCM has also the encapsulation material. The melting temperature of Micronal ${ }^{\circledR}$ was around $25^{\circ} \mathrm{C}$.

The samples used to calculate the heat capacity weighted between $25-60 \mathrm{~g}$. The values of heat capacity are shown in Table 4 and were taken in solid (around $10^{\circ} \mathrm{C}$ ) and liquid phase (around $50^{\circ} \mathrm{C}$ ) of the PCM.

The Spanish building regulation [31] states a heat capacity of $1 \mathrm{~J} / \mathrm{g} \cdot{ }^{\circ} \mathrm{C}$ for several types of mortars, which is in good agreement with the range of $0.73-0.97 \mathrm{~J} / \mathrm{g} \cdot{ }^{\circ} \mathrm{C}$ obtained for the SLM without PCM. The Cp is increased $22.5 \%$ by the addition of $10 \%$ of microencapsulated PCM, and $28 \%$ by the addition of $20 \%$ PCM.

\subsection{Fire reaction}

The results of the reaction test show the ignition and extinction times, and the average duration of the flame.

As general observations, the temperature of SLM samples without PCM increases with the application of the hot focus but are not flammable. White SLM do not change its colour with the application of the hot focus but yellow SLM suffers a variation of its colour becoming orange (Figure 11) due to the calcination of the pigment.

SLM samples have differences on the surfaces roughness and this fact can cause differences in the fire behaviour due to higher flame persistence in rough surfaces. Therefore M20 samples have been tested on both surfaces: rough and smooth. Table 5 summarizes the results obtained for the different formulations in the dripping test. As it can be observed the first ignition (TTI) occurs more frequently in M10 samples than in M20. Moreover, a higher number of ignitions are observed with M10 samples with short average combustion extent. Usually this combination is a sign of auto-extinguish capability of the material, which is important to reduce the risks of fire spread in case of fire [25]. In both SLM, yellow and white, M20 exhibit a worse fire reaction, and the flame persistence is higher in the case of rough surfaces. However, it should be noticed the remarkably high combustion extent values for the yellow M20 SLM. This fact could be due to the inhomogeneous distribution of the PCM through the sample with higher concentrations of the material on the surfaces.

\section{Conclusions}

Both single layer mortars, with and without colouring agents, show the same trends regarding the effect of PCM in their formulation. The addition of microencapsulated PCM to SLM requires higher amounts of water to maintain the same workability and it affects the hydration process achieving lower values of mechanical properties, mainly at early ages. The increase of water during mixing as well as the modification of the particle size distribution and the amount 
of cement could be some of the most important factors affecting mechanical and physical properties. To sum up, only M10 could fulfil the requirements for plaster applications since compressive strength is only reduced by $5 \%$.

Thermal conductivity and thermal diffusivity decrease with the amount of PCM due to the lower thermal conductivity of the microcapsules. The enthalpy of M10 and M20 SLM are slightly lower than 10 and $20 \mathrm{~kJ} / \mathrm{kg}$ (8.80 and 17.35, respectively) because of the material encapsulation. On the other hand, Cp is increased 22.5\% in M10, and 28\% in M20.

As expected the presence of organic PCM worsens the fire behaviour of the mortar. M10 produces flame, but exhibit auto-extinguish ability once the heat source is removed. However, samples with 20\% PCM may significantly contribute to flame spread in case of fire.

SEM images show that once the PCM is added in the final matrix, the microcapsules were dispersed along the material. Furthermore, it is demonstrated that the mixing process to prepare mortar samples does not cause the breakage of microcapsules.

\section{Acknowledgments}

The work is partially funded by the Spanish government (ENE2011-28269-C03-02 and MAT2011-26410). The authors would like to thank the Catalan Government for the quality accreditation given to their research group GREA (2014 SGR 123), research group DIOPMA (2014 SGR 1543) and research group GICITED (2014 SGR 1298).

The work leading to this invention has received funding from the European Union's Seventh Framework Programme (FP7/2007-2013) under grant agreement n PIRSES-GA-2013-610692 (INNOSTORAGE)

\section{References}

[1] International Energy Agency, Energy Technology Perspectives, 2012

[2] Directive 2010/31/eu of the European parliament and of the council of 19 May 2010 on the energy performance of buildings. Available from: http://www.epbd-ca.eu

[3] Farid MM, Khudhair AM, Razack SAK, Al-Hallaj S. A review on phase change energy storage: materials and applications. Energy Conversion \& Management 2004; 45:1597-1615

[4] Khudhair AM, Farid MM. A review on energy conservation in building applications with thermal storage by latent heat using phase change materials. Energy Conversion \& Management 2004; 45:263-275

[5] Kalnæsa SE, Jelle BP. Phase change materials and products for building applications: A state-of-the-art review and future research opportunities. Energy and Buildings 2015; 94: 150176]

[6] Aste N, Angelotti A, Buzzetti M. The influence of the external walls thermal inertia on the energy performance of well insulated buildings. Energy and Buildings 2009; 41:1181-1187

[7] Izquierdo-Barrientos MA, Belmonte JF, Rodríguez-Sánchez D, Molina AE, AlmendrosIbáñez JA. A numerical study of external building walls containing phase change materials (PCM). Applied Thermal Engineering 2012; 47:73-85

[8] Alawadhi EM. Thermal analysis of a building brick containing phase change material. Energy and Buildings 2008; 40:351-357 
[9] Jin X, Medina MA, Zhang X. On the importance of the location of PCMs in building walls for enhanced thermal performance. Applied Energy 2013; 106:72-78

[10] Entrop AG, Brouwers HJH, Reinders AHME. Experimental research on the use of microencapsulated Phase Change Materials to store solar energy in concrete floors and to save energy in Dutch houses. Solar energy 2011; 85:1007-1020

[11] Kuznik F, Virgone J. Experimental assessment of a phase change material for wall building use. Applied Energy 2009; 86:2038-2046

[12] Cabeza LF, Castellon C, Nogues M, Medrano M, Leppers R, Zubillaga O. Use of microencapsulated PCM in concrete walls for energy savings. Energy and Buildings 2007; 39:113-119

[13] Shilei LV, Neng Z, Guohui F. Impact of phase change wall room on indoor thermal environment in winter. Energy and buildings 2006; 38:18-24

[14] Schossiga P, Henninga HM, Gschwandera S, Haussmann T. Micro-encapsulatedphasechange materials integratedinto construction materials. Solar Energy Materials \& Solar Cells 2005; 89:397-306

[15] Athienitis AK, Liu C, HAWES D, BANU D, FELDMAN D. Building and environment 1997; 32:405-410

[16] Ascione F, Bianco N, Francesca De Masi R, de’ Rossi F, Vanoli GP. Energy refurbishment of existing buildings through the use of phase change materials: Energy savings and indoor comfort in the cooling season. Applied Energy 2014; 113:990-1007

[17] UNE-EN 1015-2:1999. Métodos de ensayo de los morteros para albañilería. Parte 2: Toma de muestra total de morteros y preparación de los morteros para ensayo

[18] UNE-EN 1015-3:2000. Métodos de ensayo para morteros de albañilería. Parte 3: Determinación de la consistencia del mortero fresco (por la mesa de sacudidas)

[19] Eddhahak A, Drissi S, Colin J, Care S, Neji J. Effect of phase change materials on the hydration reaction and kinetic of PCM-mortars. Journal of thermal analysis and calorimetry, 2014; 2:537 -545

[20] UNE-EN 1015-10:2000. Métodos de ensayo de los morteros para albañilería. Parte 10: Determinación de la densidad aparente en seco del mortero endurecido

[21] UNE-EN ISO 12680-1:2007. Métodos de ensayo para productos refractarios. Parte 1: Determinación del módulo de Young dinámico (MOE) por excitación de la vibración por impulse

[22] Rosell JR, Cantalapiedra IR. Simple method of dynamic Young's modulus determination in lime and cement mortars. Materiales de Construcción, 2011; 61:39-48

[23] UNE-EN 1015-11:2000. Métodos de ensayo de los morteros para albañilería. Parte 11: Determinación de la resistencia a flexión y a compresión del mortero endurecido

[24] UNE-EN 1015-12:2000. Métodos de ensayo de los morteros para albañilería. Parte 12: Determinación de la resistencia a la adhesión de los morteros de revoco y enlucidos endurecidos aplicados sobre soportes

[25] UNE 23721:1990. Ensayos de reacción al fuego de los materiales de construcción. Ensayo por radiación aplicable a los materiales rígidos o similares (materiales de revestimiento) de cualquier espesor y a los materiales flexibles de espesor superior a $5 \mathrm{~mm}$

[26] Ling TC, Poon CS. Use of phase change materials for thermal energy storage in concrete: An overview. Construction and Building Materials, 2013; 46: 55-62

[27] Cui H, Liao W, Memon SA, Dong B, Tang W. Thermophysical and Mechanical Properties of Hardened Cement Paste with Microencapsulated Phase Change Materials for Energy Storage, Materials, 2014; 7: 8070-8087 
[28] Hunger M, Entrop AG, Mandilaras I, Brouwers HJH, Founti M. The behavior of selfcompacting concrete containing micro-encapsulated Phase Change Materials, Cement \& Concrete Composites, 2009; 31: 731-743

[29] Norvell C, Dusicka, P, D.J. Sailor, The effect of microencapsulated phase-change material on the compressive strength of structural concrete. J. Green Building, 2013; 8 (3): 116-124.

[30] Lecompte T, Le Bideaua P, Glouanneca P, Nortershauserb D, Le Masson S. Mechanical and thermo-physical behaviour of concretes and mortars containing phase change material, Energy and Buildings, 2015; 94: 52-60

[31] Código Técnico de la Edificación - Documento Básico: Seguridad en Caso de Incendio. Ministerio de Fomento (CTE). REAL DECRETO. February 2010 


\section{Tables}

Table 1. Bulk density, relative density and porosity of samples under study

\begin{tabular}{|l|c|r|r|r|r|r|r|}
\hline SAMPLE & $\begin{array}{c}\text { PCM } \\
(\%)\end{array}$ & $\begin{array}{c}\text { Hydrostatic } \\
\text { weight } \\
\left(\mathrm{g} / \mathrm{cm}^{3}\right)\end{array}$ & $\begin{array}{c}\text { Saturated } \\
\left(\mathrm{g} / \mathrm{cm}^{3}\right)\end{array}$ & $\begin{array}{c}\text { Dry } \\
\text { weight } \\
\left(\mathrm{g} / \mathrm{cm}^{3}\right)\end{array}$ & $\begin{array}{c}\text { Bulk } \\
\text { density } \\
\left(\mathrm{g} / \mathrm{cm}^{3}\right)\end{array}$ & $\begin{array}{c}\text { Relative } \\
\text { density } \\
\left(\mathrm{g} / \mathrm{cm}^{3}\right)\end{array}$ & $\begin{array}{c}\text { Porosity } \\
(\%)\end{array}$ \\
\hline W/M0 & 0 & 59.44 & 91.31 & 61.87 & 1.34 & 2.62 & 49.5 \\
\hline W/M10 & 10 & 63.28 & 109.03 & 77.50 & 1.22 & 2.44 & 49.8 \\
\hline W/M20 & 20 & 56.05 & 102.35 & 74.92 & 1.04 & 2.06 & 48.9 \\
\hline Y/M0 & 0 & 56.88 & 100.77 & 71.16 & 1.25 & 2.61 & 52.1 \\
\hline Y/M10 & 10 & 60.75 & 105.42 & 74.56 & 1.23 & 2.49 & 50.8 \\
\hline Y/M20 & 20 & 69.46 & 108.29 & 73.67 & 1.06 & 2.11 & 49.8 \\
\hline
\end{tabular}

Table 2. Thermal diffusivity $\left[\mathrm{m}^{2} / \mathrm{s}\right]$

\begin{tabular}{|l|c|c|c|}
\cline { 2 - 4 } \multicolumn{1}{c|}{} & $0 \%$ Micronal ${ }^{\circledR}$ & $10 \%$ Micronal ${ }^{\circledR}$ & $20 \%$ Micronal \\
\hline White SLM & $3.47 \cdot 10^{-7}$ & $3.25 \cdot 10^{-7}$ & $3.22 \cdot 10^{-7}$ \\
\hline Yellow SLM & $4.01 \cdot 10^{-7}$ & $3.31 \cdot 10^{-7}$ & $3.04 \cdot 10^{-7}$ \\
\hline
\end{tabular}

Table 3. Melting enthalpy by DCS analysis

\begin{tabular}{|l|l|c|c|}
\hline Parameter & Units & M10 & M20 \\
\hline $\mathrm{T}_{\text {initial }}$ & $\left({ }^{\circ} \mathrm{C}\right)$ & 10.88 & 10.64 \\
\hline $\mathrm{T}_{\text {final }}$ & $\left({ }^{\circ} \mathrm{C}\right)$ & 26.33 & 25.94 \\
\hline $\mathrm{Tm}_{\mathrm{PCM}}$ & $\left({ }^{\circ} \mathrm{C}\right)$ & 24.74 & 25.16 \\
\hline $\mathrm{Hm}$ & $(\mathrm{kJ} / \mathrm{kg})$ & 8.80 & 17.35 \\
\hline
\end{tabular}

Table 4. Heat capacity by DCS analysis

\begin{tabular}{|l|l|r|r|r|}
\hline Parameter & Unit & \multicolumn{1}{c|}{ M0 } & \multicolumn{1}{c|}{ M10 } & \multicolumn{1}{c|}{ M20 } \\
\hline $\mathrm{T}_{\text {solid }}$ & $\left({ }^{\circ} \mathrm{C}\right)$ & 10.48 & 10.48 & 10.24 \\
\hline Cp $_{\text {solid }}$ & $\left(\mathrm{J} / \mathrm{g}^{\circ} \mathrm{C}\right)$ & 0.73 & 0.91 & 0.92 \\
\hline $\mathrm{T}_{\text {liquid }}$ & $\left({ }^{\circ} \mathrm{C}\right)$ & 49.47 & 49.40 & 49.47 \\
\hline Cp pliquid & $\left(\mathrm{J} / \mathrm{g}^{\circ} \mathrm{C}\right)$ & 0.97 & 1.16 & 1.26 \\
\hline
\end{tabular}

Table 5. Results obtained in dripping test

\begin{tabular}{|c|c|c|c|}
\cline { 2 - 4 } \multicolumn{1}{c|}{} & TTI (s) & Nr of ignitions & Avg. combustion extent (s) \\
\hline W 0\% PCM & - & - & - \\
\hline W 10\% PCM & 27 & 35 & 4 \\
\hline WR 20\% PCM & 13 & 9 & 31 \\
\hline WL 20\% PCM & 14 & 13 & 20 \\
\hline Y 0\% PCM & - & - & - \\
\hline Y 10\% PCM & 23 & 43 & 4 \\
\hline YR 20\% PCM & 11 & 2 & 253 \\
\hline YS 20\% PCM & 10 & 2 & 202 \\
\hline
\end{tabular}




\section{Figure Captions}

Figure 1. A) Equipment used in fundamental resonance frequency test. B) Scheme [19] of the position of holders and impact zones (a) for $\mathrm{MOE}_{\text {flex }}$ and (b) for $\mathrm{MOE}_{\text {long }}$

Figure 2. A) Samples fixed in the holder by dual-component resins B) Adhesion tester device

Figure 3. A) Outer of the combustion chamber B) Inner of the combustion chamber

Figure 4. SEM images of Micronal ${ }^{\circledR} 5001$

Figure 5. SEM images of SLM with $20 \%$ of PCM

Figure 6. Flexural (left) and longitudinal (right) $\mathrm{MOE}_{\mathrm{D}}$ at different SLM ages

Figure 7. Results of compressive strength test

Figure 8. Values of single layer mortar adherence

Figure 9. Thermal conductivity of single layer mortar

Figure 10. DSC curves of SLM with 10\% PCM (left) and SLM with 20\% PCM (right)

Figure 11. Yellow SLM. Left) before fire reaction test. Right) after fire reaction test 

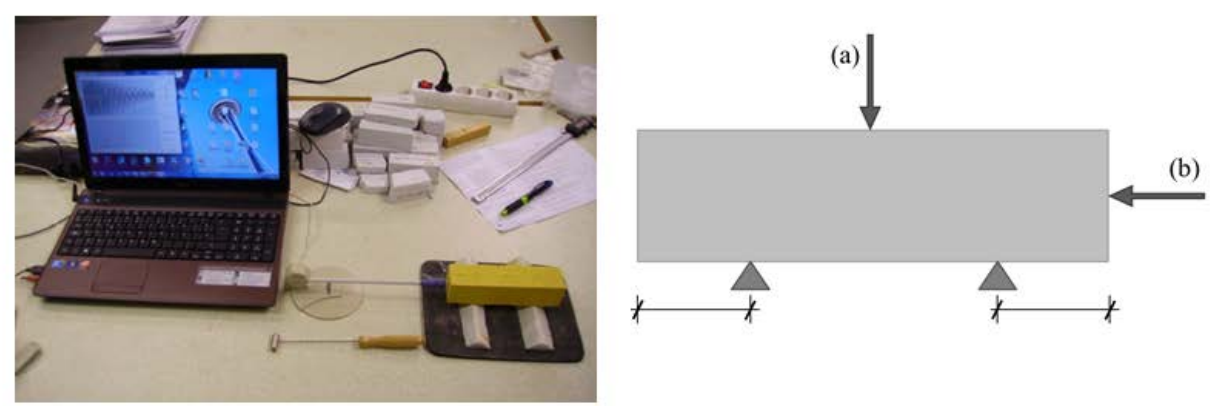

Figure 1 

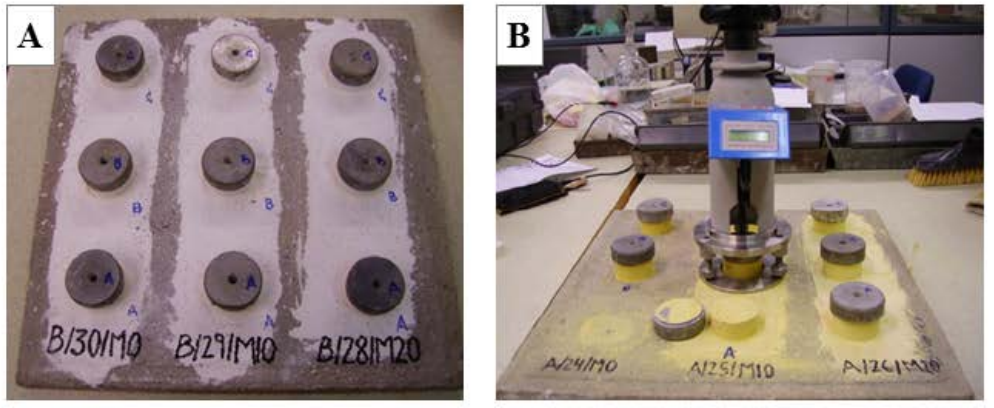

Figure 2 


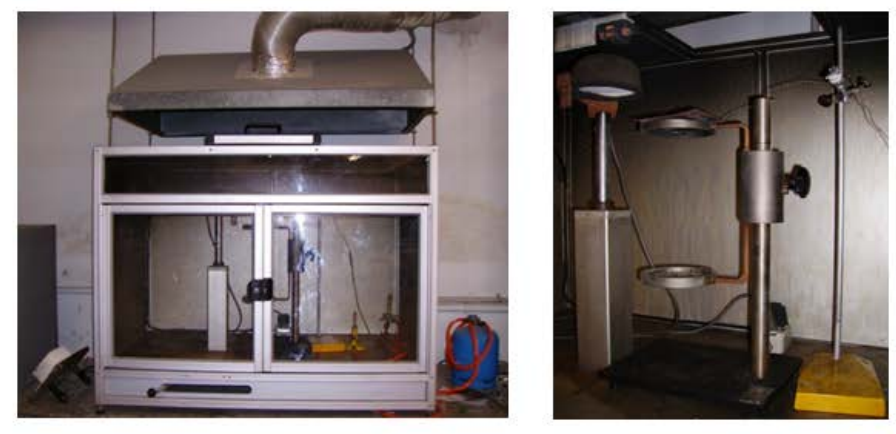

Figure 3 

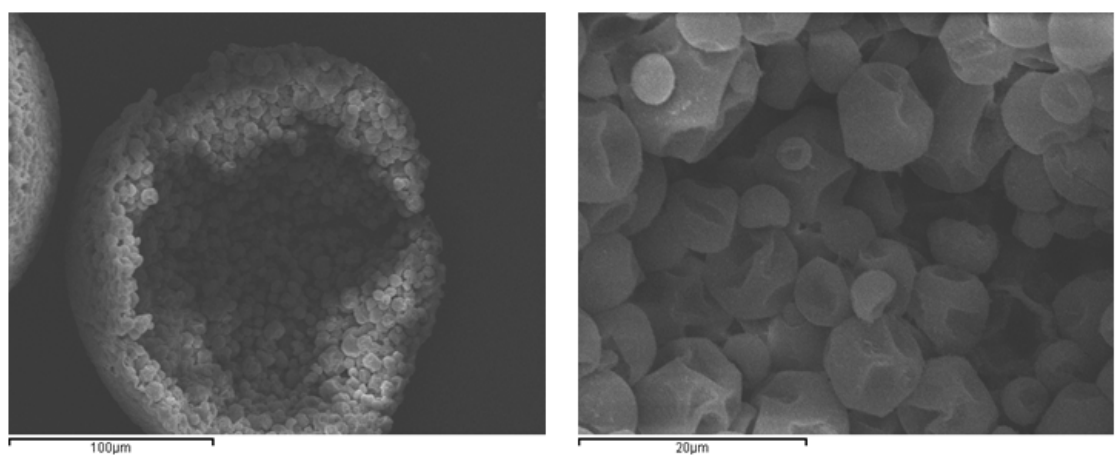

Figure 4 


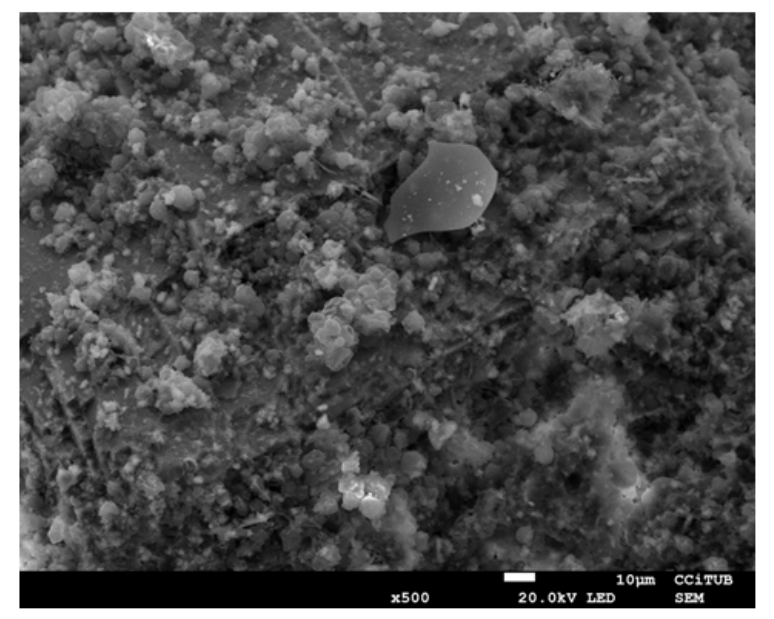

Figure 5 


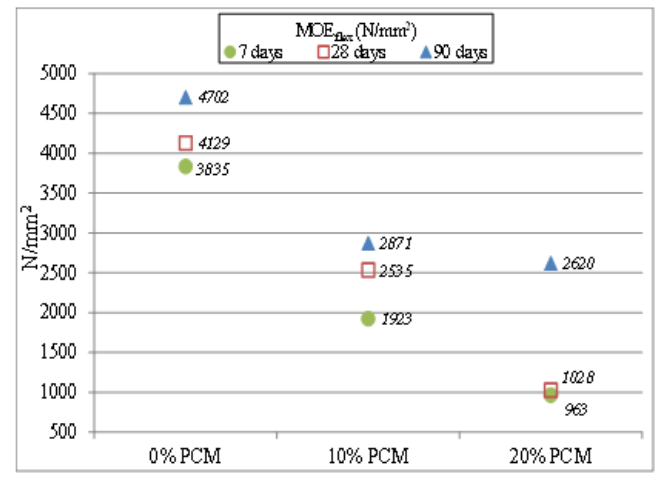

\begin{tabular}{|c|c|c|c|}
\hline \multirow{2}{*}{4000} & & $\begin{array}{c}\mathrm{MOE}_{\text {bar }}\left(\mathrm{N} / \mathrm{mmm}^{2}\right) \\
\text { 07 days } \quad \square 28 \text { days } \quad \triangle 90 \text { days }\end{array}$ & \\
\hline & $\triangle 3914$ & & \\
\hline 3500 & $\begin{array}{l}3329 \\
3175\end{array}$ & & \\
\hline 3000 & \multicolumn{3}{|c|}{$\Delta 2599$} \\
\hline \multirow{2}{*}{$\begin{array}{l}2500 \\
2000 \\
S_{2}\end{array}$} & \multicolumn{2}{|r|}{$\square 2252$} & $\hat{\Delta}_{2113}^{2289}$ \\
\hline & \multicolumn{3}{|c|}{1680} \\
\hline $\begin{array}{l}1500 \\
1000\end{array}$ & \multicolumn{3}{|r|}{$\square 964$} \\
\hline 00 & $0 \% \mathrm{PCM}$ & $10 \% \mathrm{PCM}$ & $20 \%$ PCM \\
\hline
\end{tabular}

Figure 6 


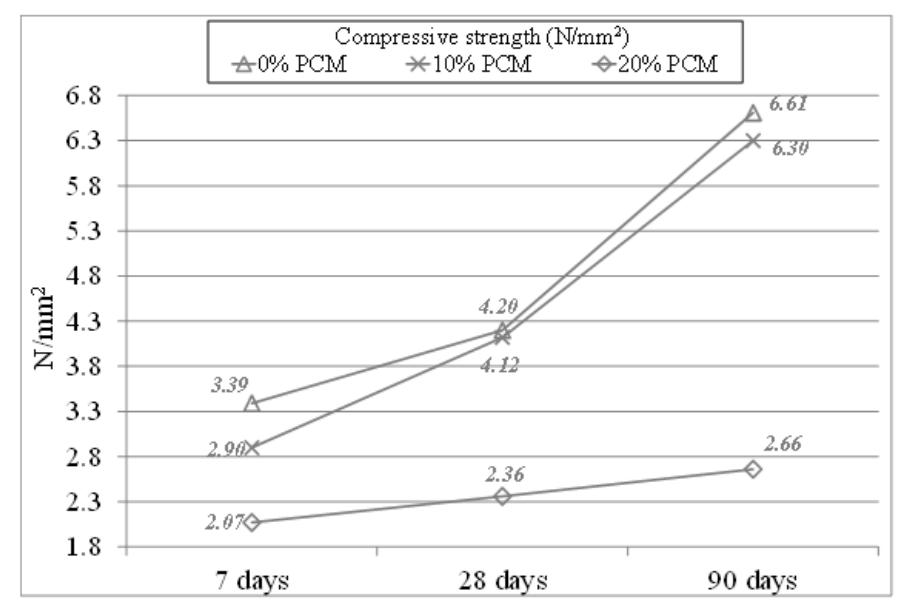

Figure 7 


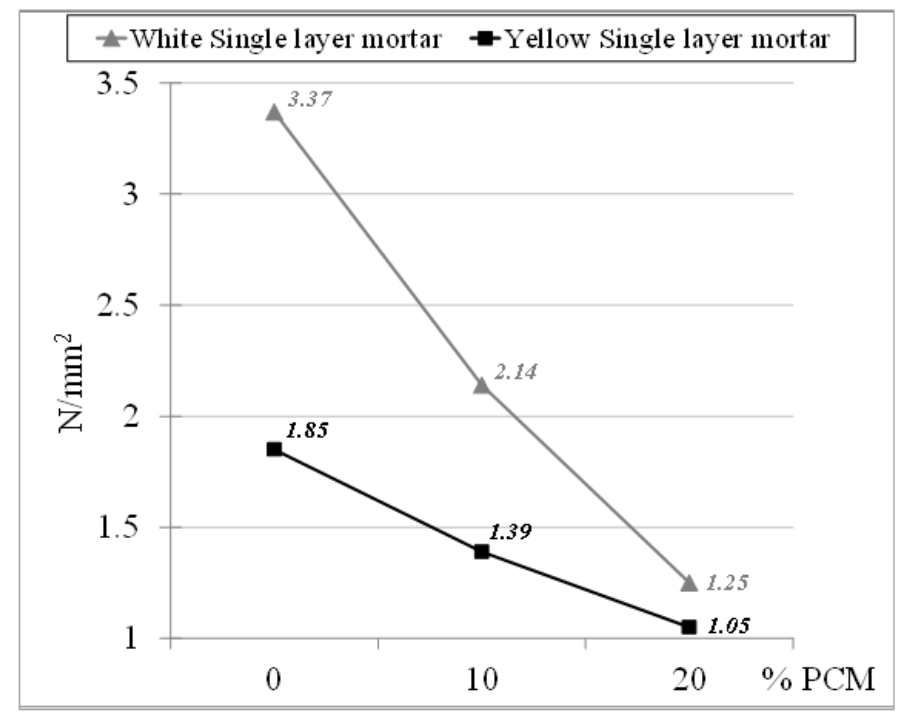

Figure 8 


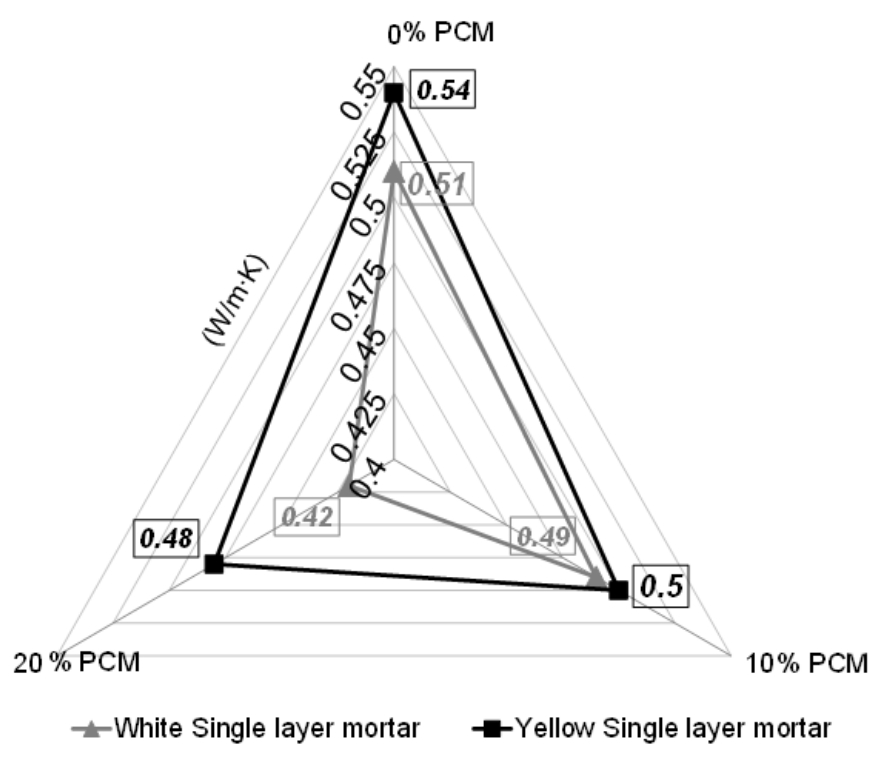

Figure 9 

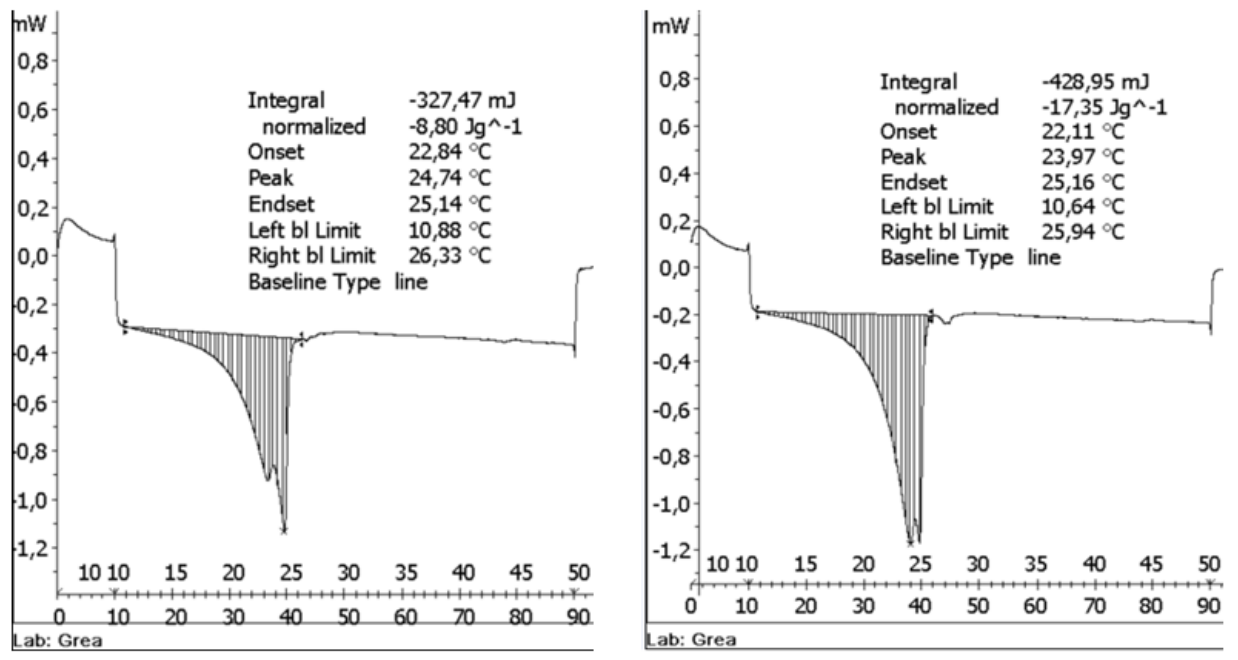

Figure 10 

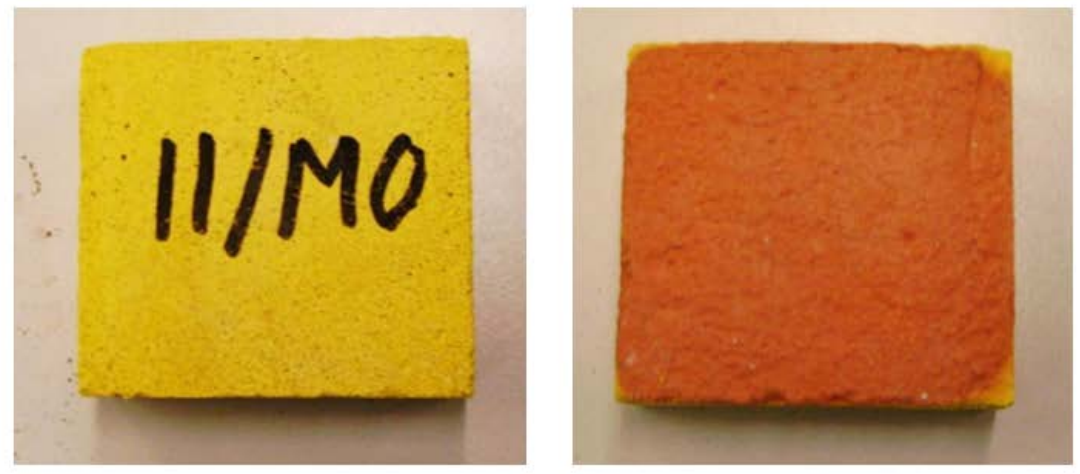

Figure 11 